Abstracta Iranica Abstracta Iranica

Revue bibliographique pour le domaine irano-aryen

Volume 42-43 | 2021

Comptes rendus des publications de 2019-2020

\title{
Valentina Laviola. Islamic Metalwork from Afghanistan (9th-13th Century): The Documentation of the IsMEO Italian Archaeological Mission
}

Viola Allegranzi

\section{(2) OpenEdition}

1 Journals

Édition électronique

URL : https://journals.openedition.org/abstractairanica/53961

DOI : 10.4000/abstractairanica.53961

ISSN : 1961-960X

Éditeur :

CNRS (UMR 7528 Mondes iraniens et indiens), Éditions de l'IFRI

Référence électronique

Viola Allegranzi, «Valentina Laviola. Islamic Metalwork from Afghanistan (9th-13th Century): The Documentation of the IsMEO Italian Archaeological Mission », Abstracta Iranica [En ligne], Volume 42-43 | 2021, document 14, mis en ligne le 30 décembre 2021, consulté le 12 décembre 2022. URL : http:// journals.openedition.org/abstractairanica/53961; DOI : https://doi.org/10.4000/abstractairanica. 53961

Ce document a été généré automatiquement le 12 décembre 2022.

Tous droits réservés 


\title{
Valentina Laviola. Islamic Metalwork from Afghanistan (9th-13th Century): The Documentation of the IsMEO Italian Archaeological Mission
}

\author{
Viola Allegranzi
}

\section{RÉFÉRENCE}

Valentina Laviola. Islamic Metalwork from Afghanistan (9th-13th Century): The Documentation of the ISMEO Italian Archaeological Mission. Napoli: UniorPress, 2020, 554 p., (Series Maior XI / Serie Orientale Roma 24), ISBN : 978-88-6719-191-8

1 Les métaux de l'Iran médiéval nous sont connus par des catalogues qui rassemblent en majorité des objets de luxe et richement ornés, acquis dans le passé par différentes collections publiques ou privées. Le catalogue ici décrit une toute autre conception, car il recense les métaux relevés entre 1957 et 1979 par la Mission Archéologique Italienne dans plusieurs sites et musées de l'Afghanistan. Il dévoile ainsi une collection méconnue, dispersée et en large partie perdue, que l'auteur reconstitue à partir des archives de la Mission italienne, dans le but d'en préserver la mémoire. Les chiffres donnent la mesure de l'effort accomplit: parmi les 439 métaux inclus dans le catalogue, 337 sont inédits et seuls 47, acheminés en Italie par la mission et actuellement conservés à Rome (Museo delle civiltà - section Arte Orientale), ont pu être examinés personnellement par Laviola. L'auteur s'attache à recouper les photos anciennes parfois partielles -, les rares publications, et les annotations des archéologues, pour documenter un corpus d'objets, parfois très fragmentaires, qui est d'autant plus intéressant qu'il contient des spécimens rarement représentés dans les collections occidentales. 
2 À la suite d'une introduction portant sur les activités de la Mission italienne et les lieux de découverte des objets, le catalogue constitue l'essentiel de l'ouvrage: les métaux sont organisés selon leurs fonctions (vaisselle de table, équipements de cuisine, d'ablutions, luminaires, etc.) et illustrés par des photos en noir et blanc. Les chapitres conclusifs sont consacrés aux considérations globales sur la morphologie des objets, leur décor et les inscriptions - pour la plupart desquelles une lecture originale est proposée. L'analyse menée par l'auteur est à la fois synthétique et précise, et nourrit plusieurs hypothèses concernant l'attribution chronologique et le développement stylistique des différentes classes d'objets. Une attention particulière est portée aux pièces provenant des sites archéologiques de Ghazni qui s'avère avoir été un centre de production majeur, associé à des séries caractéristiques, telle que celle des objets en alliages de bronze à haute teneur en étain. L'ouvrage se termine par une bibliographie (13 p.), suivie d'une série d'annexes : une table des lieux de conservation des métaux étudiés (annexe $\mathrm{A}$ ), un tableau de concordance du catalogue (annexe $\mathrm{B}$ ), une synthèse des formes d'objets classés selon leur fonction (annexe C), et surtout une table des métaux découverts en contexte archéologique (annexe D). Il faut enfin saluer l'utilité des quatre index sur lesquels se referme ce livre, avec notamment un index des termes et formules recensés dans les inscriptions (index I), et un rigoureux index général des noms (index II), lieux (index III) et auteurs (index IV). Dans sa double dimension de catalogue raisonné et document historiographique, cette publication marque une avancée importante dans la connaissance des arts du métal dans l'Iran oriental prémongol, tout en contribuant à la valorisation du patrimoine culturel afghan, souvent menacé, voire disparu.

\section{AUTEURS}

\section{VIOLA ALLEGRANZI}

Institut für Iranistik der ÖAW, Wien 